\title{
La influencia de Abraham Cohen de Herrera en la Filosofía Natural del siglo XvII: su impronta en los Principia Philosophiae de Anne Conway
}

\author{
Hernán Matzkevich \\ Purdue University
}

La filosofía natural del siglo XVII comparte con el pensamiento del XVI rasgos de misticismo hermético-cabalístico y neoplatonismo. Las obras que presentan este legado, lejos de representar accidentes o casos aislados, constituyen el magma intelectual en el cual se gestaron muchos de los debates que marcaron la ciencia moderna. Representante paradigmática de esta corriente es Anne Conway, quien en sus Principia Philosophiae realiza un ataque al mecanicismo y al dualismo de cuño cartesiano apoyándose en doctrinas emanantistas, monistas y espiritualistas de la materia que toma directamente de la tradición cabalística luriánica representada por Abraham Cohen de Herrera y su Puerta del Cielo.

Palabras Clave: siglo XVII; cábala; neoplatonismo; Temprana Modernidad; Abraham Cohen de Herrera; Anne Conway.

The Influence of Abraham Cohen de Herrera in $17^{\mathrm{TH}}$-Century Natural Philosophy: His Impression on Anne Conway's Principia Philosophiae.- Natural Philosophy of the $17^{\text {th }}$ Century shares traits of hermetic-cabalistic mysticism and neoplatonism of the $16^{\text {th }}$ Century. Works presenting this legacy, far from representing isolated cases, constitute the intelectual magma in which many of the debates which signed modern science were gestated. One of the paradigmatic representation of this stream is Anne Conway, who in her Principia Philosophiae attacks the Cartesian mechanism and dualism, supporting herself in monistic and espiritualistic doctrins of the matter that she takes directly from Isaac Luria's cabalistic tradition represented by Abraham Cohen de Herrera and his Puerta del Cielo.

KeYwords: Seventeenth Century; Kabbalah; Neoplatonism; Early Modern Period; Abraham Cohen de Herrera; Anne Conway.

\footnotetext{
*hmatzkev@purdue.edu
} 


\section{INTRODUCCIÓN}

Tradicionalmente se ha entendido el pensamiento del siglo XVII en términos de ruptura con las tradiciones herméticas, astrológicas, alquímicas, cabalísticas y neoplatónicas que caracterizaron a las producciones intelectuales del siglo precedente. Conforme a esta visión, el siglo XVII, depurado de ese bagaje esotérico, asistirá a la fundación de la ciencia moderna, celosamente tutelada por el método cartesiano y la claridad y distinción epistemológica que este demandaba. Esta visión rupturista ha sido revisada durante las últimas décadas, afirmando en su lugar un continuismo entre ambos períodos. Tal revisión estuvo directamente vinculada a las investigaciones en torno a los manuscritos inéditos de Newton. Estas mostraron el interés del autor por materias como la teología, la alquimia y el hebraísmo ${ }^{1}$. Semejantes intereses poco tenían que ver con la imagen que habían trazado de Newton los relatos positivistas, que hacían de él un paladín de la pura racionalidad científica moderna. Más importante aún, estos trabajos hicieron trastabillar la visión rupturista de un siglo XVII racional-cientificista respecto a un siglo XVI neoplatónico-ocultista ${ }^{2}$.

\footnotetext{
${ }^{1}$ Si bien en los últimos años los textos herméticos, alquímicos y teológicos de Newton han sido objeto de numerosos estudios, cabe destacar cómo estos tuvieron su origen en las obras de B. J. Dobis, The Foundations of Newton's Alchemy. Or "The Hunting of the Greene Lyon" (Cambridge 1975); R. S. WestFall, «Newton and Alchemy», en Occult and Scientific Mentalities in the Renaissance, ed. B. Vickers (Cambridge 1984) y P. M. Rattansi, «Newton's Alchemical Studies», en Science, Medicine and Society in the Renaissance. Essays to Honor Walter Pagel, ed. A. G. Debus (New York 1972) vol. II, págs. 167-182. Para una bibliografía actualizada de los estudios sobre Newton y del conjunto de sus manuscritos véase The Newton Project, dirigido por R. ILIFFE (http:// www.newtonproject.sussex.ac.uk).

${ }^{2}$ No se puede eludir la mención de la gran labor que a este respecto efectuaron los intelectuales vinculados al Instituto Warburg, entre los cuáles es posible citar nombres como los de P. Kristeller, E. Garin o F. Yates. Sobre la historia intelectual del Instituto Warburg véase J. E. BurucúA, Historia, arte, cultura: De Aby Warburg a Carlo Ginzburg (Buenos Aires 2002). Respecto a F. A. Yates, su trabajo Giordano Bruno y la tradición hermética (Barcelona 1964) constituyó un ejemplo que muchos siguieron en el futuro. Con posterioridad a Yates, figuras como D. P. Walker, A. G. Debus, P. M. Rattansi y Ch. Webster argumentaron a favor de no segregar las tradiciones alquímicas, herméticas, astrológicas, numerológicas y cabalísticas como tradiciones abandonadas conforme tuvo lugar el despliegue del pensamiento racional en el siglo XVII. A este respecto es posible consultar, entre otras muchas: D. P. WALKER, Spiritual and Demonic Magic. From Ficino to Campanella (London 1958); A. G. Debus, Man and Nature in
} 
Paulatinamente fue preciso asumir también como propio del espíritu intelectual del siglo XVII la presencia de obras sincréticas donde confluían formas de magia, misticismo neoplatonizante y esoterismos de toda índole con la búsqueda de un conocimiento preciso del mundo natural. Esta fusión será finalmente aceptada como un rasgo característico del pensamiento de la época: buena parte de la filosofía del siglo XVII bebe de las fuentes que afirman la teoría de las simpatías, las signaturas y la unidad substancial de la creación, continúa operando con la noción neoplatónico-renacentista del hombre como microcosmos, afirma la capacidad humana de operar sobre las fuerzas ocultas de la naturaleza y no clausura ni abandona los laboratorios alquímicos. Esta filosofía sincrética no es un accidente en su tiempo, una permanencia reaccionaria y supersticiosa de instancias superadas: constituye ni más ni menos que el territorio donde germinó la ciencia moderna. Filósofos naturales como Francis Mercury van Helmont o Christian Knorr von Rosenroth, interesados por la trasmutación de los metales y la elaboración de la piedra filosofal, la cábala judía y el hermetismo, eran hijos legítimos de su tiempo, tanto como Leibniz o Newton, quienes por otra parte, compartían esos mismos intereses que de alguna manera influenciaron la elaboración de sus sistemas físicos y metafísicos.

Ejemplo paradigmático de esta síntesis entre tradiciones neoplatónico-cabalísticas y ciencia durante el siglo XVII es Anne Conway ${ }^{3}$.

the Renaissance (Cambridge 1978); P. M. RatTAnsi, «Some Evaluations of Reason in Sixteenth and Seventeenth Century Natural Philosophy», en Changing Perspectives in the History of Science. Essays in Honour of Joseph Needham, eds. M. Teich y R. Young (London-Dordrecht 1973); Ch. Webster, From Paracelsus to Newton: Magic and the Making of Modern Science (Cambridge 1982).

${ }^{3}$ En relación a la bibliografía existente sobre Anne Conway cabe mencionar, entre otros trabajos: M. CRitchley, «The Malady of Anne, Viscountess Conway», King's College Hospital Gazette 16 (1937) págs. 44-49; C. Merchant, «The Vitalism of Anne Conway: Its Impact on Leibniz Concept of the Monad», Journal of the History of Philosophy 7 (1979) págs. 255-269; J. Duran, «Anne Viscountess Conway: A Seventeenth-Century Rationalist», Hypatia: A Journal of Feminist Philosophy 4 (1980) págs. 64-79; L. Frankel, «Anne Finch, Viscountess Conway», en A History of Women Philosophers, ed. M. E. Waith, vol. III (Dordrecht 1991) págs. 41-58; S. Hutton, Ancient Wisdom and Modern Philosophy: Anne Conway, F.M. Van Helmont and the Seventeenth-Century Dutch Interchange of Ideas (Utrecht 1994); S. HutTon, «Anne 
Esta autora escribió un único tratado, en el cual buscaba defender su propia teoría de la materia, oponiéndose directamente al mecanicismo de Spinoza, Descartes y Hobbes. Su propia argumentación, cimentada en un monismo espiritualista, se apoya directamente en las doctrinas de la emanación y el mundo físico desarrolladas por Abraham Cohen de Herrera en su tratado Puerta del Cielo ${ }^{4}$. Para Lady Conway la verdadera sabiduría de la Antigüedad y las respuestas a los interrogantes del mundo físico moraban en aquellas escrituras arcanas provenientes de la tradición judía que las clases cultas europeas estaban redescubriendo. Los textos de Moisés de León, Hayim Vital, Israel Sarug y Abraham Cohen de Herrera, pasaron a considerarse como el eslabón inicial, la expresión más directa de esa cadena de saber inspirado que se remontaba a la misma divinidad.

Esta es por tanto la historia de una sensibilidad capaz de sumergirse en las místicas profundidades de la tradición judía en búsqueda de respuestas para los problemas científicos de su tiempo; una sensibilidad que en el lenguaje de la cábala halló las claves gnoseológicas para desentrañar el Libro de la Naturaleza.

Conway, critique de Henry More: substance et matière», Archives de Philosophie 58 (1995) págs. 371-384; S. Hutton, «Anne Conway, Margaret Cavendish and Seventeenth Century Thought», en Women, Science and Medicine 1500-1700. Mothers and Sisters of The Royal Society, eds. L. Hunter y S. Hutton (Stroud 1997); M. ${ }^{a}$ I. Perdomo Reyes, «La Filosofía de la Naturaleza de Lady Anne Conway», en Actas del II Congreso de la Sociedad de Lógica, Metodología y Filosofía de la Ciencia en España, coord. A. Estany y D. Quesada (Bellaterra 1997) págs. 316-319; S. Hutton, «Henry More, Anne Conway and the Kaballah A Cure for the Kabbalistic Nightmare?», en JudaeoChristian Intellectual Cuture in the Seventeenth Century. A Celebration of the Library of Narcissus Marsh, in Dublin, eds. A. P. Coudert, S. Hutton, R. H. Popkin y G. M. Weiner (Dordrecht 1999) págs. 27-42; M. ${ }^{a}$ I. Perdomo Reyes, «Las contribuciones olvidadas de las mujeres de ciencia: Los casos de Anne Conway y Emilie deu Châtelet», en Ciencia y Género, eds. E. Pérez Sedeño y P. Alcalá Cortijo (Madrid 2001) págs. 233-250; S. Hutton, Anne Conway: A Women Philosopher (Cambridge 2004); M. Alic, El legado de Hipatia (México D.F.-Buenos Aires-Madrid 2005) págs. 17-24; Á. García CALDERón, «El Enfrentamiento entre "New Science" y Literatura en el siglo XVII en Inglaterra: La cosmología vitalista de Anne Conway», Skopos: Revista Internacional de Traducción e Interpretación 3 (2013) págs. 49-62.

${ }^{4}$ R. Popkin, «The Spiritualistic Cosmologies of Henry More and Anne Conway», en Henry More (1618-1687): Tercentenary Studies, ed. S. Hutton (Dordrecht 1990) págs. $97-114$. 


\section{Anne Conway: FILOSOFÍA Y ENFERMEDAD}

Anne Finch -posteriormente Lady Conway a partir de su enlace con Sir Eduard Conway- nació el 14 de diciembre de $1631^{5}$. No obstante el hecho de haber sido privada de una educación formal, Lady Conway aprendió tempranamente latín, griego y francés a la vez que leía todo lo que caía en sus manos, satisfaciendo su ferviente curiosidad intelectual de forma desordenada y asistemática. Allende las limitaciones formativas que la época imponía a su género, su precaria salud también la apartó de un programa sistemático de educación ${ }^{6}$. A los doce años padeció fiebres que dejaron como secuela crónica intensos dolores de cabeza que con los años se agravaron y llegaron en ocasiones a invalidarla. Aunque forzada a permanecer largas temporadas postrada en su lecho, esto no sosegó la inquietud de espíritu de Anne Finch. En este punto su biografía se vuelve un material íntimamente entretejido con su filosofía, pues este desorden en su educación filosófica, digno a simple vista de ser lamentado, estimuló en Anne Finch una sensibilidad sincrética. No sólo la anarquía de sus lecturas configuró su actitud filosófica, sino también sus padecimientos físicos: sus Principia son una auténtica filosofía surgida del dolor, una filosofía que va detrás del fármaco que lo aniquile definitivamente.

En el destino de su trayectoria intelectual, su medio hermano, John Finch, desempeñará un papel decisivo presentándole a su tutor en Cambridge: Henry More ${ }^{7}$. Este asumirá por correspondencia la tutela de los

${ }^{5}$ Todo el contenido biográfico que a continuación se desarrolla fue elaborado a partir de las Conway Letters, editadas por S. Hutton (Oxford 1992). Esta edición de la correspondencia de Anne Conway revisa y añade material inédito a la versión llevada a cabo por M. Nicolson (New Haven 1930). En virtud de su exhaustividad fue asimismo de gran ayuda Hutton, Anne Conway.

${ }^{6}$ Este alejamiento de los programas universitarios no supone un detalle menor en el contexto del desarrollo filosófico en el contexto que nos ocupa sino un signo de la época que tendrá unas consecuencias específicas para el mismo. A este respecto véase $\mathrm{S}$. Hutton, The Oxford History of Philosophy (Oxford 2015) pág. 22.

${ }^{7}$ Sobre Henry More y los platónicos de Cambridge, así como su vínculo con el hebraísmo del XVII, es posible consultar, entre otros trabajos: A. KoYrÉ, From the Closed World to the Infinite Universe (Baltimore 1957); A. P. COUdERT, «A Cambridge Platonist's Kabbalist Nightmare», Journal of the History of Ideas 36.4 (1975) págs. 633-652; B. P. Copenhaver, «Jewish Theologies of Space in the Scientific Revolution: 
estudios de Anne Conway, siendo recibido posteriormente y con prontitud en Kensington House. De las cartas que han llegado hasta nosotros dirigidas por More a su discípula, vemos que su programa pedagógico estaba fundamentalmente basado en la nueva filosofía del cartesianismo, corriente con la que más tarde, tutor y discípula, entrarían en conflicto .

En 1650 Anne Finch contrajo matrimonio con Edward Conway, a través de quien recibe el título de Vizcondesa de Conway. Edward Conway, preocupado por buscar alivio para las constantes jaquecas que torturaban a su mujer, solicitó la presencia, primero en Kensignton House y más tarde en Ragley Hill, de los mejores médicos del momento. Pero ni siquiera la mejor asistencia médica que pudieron prodigarle contribuyó a sanar a su esposa, lo cual no significó que Sir Conway cejara en sus intentos por mejorar su calidad de vida. Es así como llega a sus oídos la fama de Francis Mercury van Helmont, quien sería, junto a Henry More, la segunda figura determinante en la formación de Anne Conway y su principal influencia en el desarrollo último de sus especulaciones metafísicas ${ }^{9}$.

Aunque fue requerido en Ragley Hill como médico, Van Helmont tuvo el mismo éxito que sus predecesores -es decir, ninguno- en el tratamiento prescripto a la enferma. La importancia de Van Helmont para Conway no radicará por tanto en los beneficios que este pudiera reportar para su endeble organismo, sino en el mundo de carácter filosófico, mágico, místico y religioso que desplegó ante ella. Es posible especular que la formación heterodoxa de ambos personajes favoreciera su notable entendimiento. Aunque de vasta erudición, Van Helmont tampoco era un hombre de la

Henry More, Joseph Rawson, Isaac Newton and their Predecessors», Annals of Science 37 (1980) págs. 488-548; S. Hutton (ed.), Henry More (1614-1687): Tercentenary Studies (Dordrecht 1990); G. A. J. Rogers, J.-M. Vienne y Y. C. Zarka (eds.), The Cambridge Platonists in Philosophical Context: Politics, Metaphysics and Religion (Dordrecht 1997); R. Bond, L'onnipresenza di Dio. Saggio su Henry More (Catanzaro 2001); R. CRocker, Henry More, 1614-1687: A Biography of the Cambridge Platonist (Dordrecht 2003).

${ }^{8}$ Sobre esta cuestión véase A. GABBEY, «Henry More and the Limits of Mechanism», en Henry More (1614-1687): Tercentenary Studies, ed. S. HutTon (Dordrecht 1990) págs. 19-35.

${ }^{9}$ Sobre Francis Mercury Van Helmont véase A. P. Coudert, The Impact of the Kabbalah in the Seventeenth Century. The Life and Thought of Francis Mercury Van Helmont (Leiden 1999) págs. 153-270. 
academia. Conforme a sus propias palabras, jamás había pisado una universidad, cosa de la cual se jactaba. De la misma manera, nunca ocultó que su conocimiento del latín, la lengua franca entre las élites intelectuales del momento, era bastante rudimentario. Había aprendido griego y hebreo por la lectura comparada de las Sagradas Escrituras y junto al de médico se contaban entre sus oficios el de tornero, tejedor, destilador de bebidas, constructor de espejos, alquimista e impresor. Hay que mencionar además su perpetua búsqueda espiritual que le valió ser encarcelado por la Inquisición y ser odiado por protestantes, quienes lo consideraban un emisario del Papa, un jesuita y un franciscano; los católicos lo juzgaban a su vez como un anarquista, anabaptista y cuáquero; ambos grupos coincidían en describirlo como un ateo, el peor calificativo imaginable en la época. En cuanto a su formación médica, esta estuvo completamente marcada por su padre, el médico paracelsiano Jean Baptista van Helmont, acérrimo crítico de la medicina galénica que dominaba las facultades durante este período.

Fue hacia 1653 cuando la familia Conway intentó por primera vez ponerse en contacto con Van Helmont; tuvieron que pasar aún diecisiete años para que los Conway lograran dar con él para solicitarle una consulta en Ragley Hill. Esto se vio favorecido gracias a una visita que Van Helmont realizó a Henry More, quien, por los motivos ya expuestos, estaba en estrecho contacto con las familias Finch y Conway. En 1670, Van Helmont viajó a Inglaterra por motivo de una misión encomendada por la Princesa Elizabeth del Palatinado, aprovechando la ocasión para reunirse con More, para quien traía una carta del hebraísta Christian Knorr von Rosenroth ${ }^{10}$. En la mencionada carta, Von Rosenroth convocaba a More a participar en el proyecto de recuperación y edición de la «antigua filosofía judaica». Este proyecto culminaría con la publicación en Alemania, en 1677, de Kabbala Denudata, volumen que recopilaba en traducción al latín, una serie de textos procedentes de la tradición cabalística judía que hasta entonces no se hallaban disponibles para los lectores europeos no judíos ${ }^{11}$.

${ }^{10}$ Sobre Von Rosenroth es posible consultar: K. SALECKER, Christian Knorr von Rosenroth (1636-1689) (Leipzig 1931) y G. Scholem, Grandes temas y personalidades de la Cábala (Barcelona 1994) págs. 243-245.

${ }^{11}$ Kabbala Denudata seu doctrina hebraeorum trascendentalis et metaphysica atque theologica opus antiquissimae philosophiae barbaricae variis speciminibus refertissimum (Sulzbach 1677-78; Frankfurt 1684). 
El encuentro entre el platónico de Cambridge y Van Helmont permitió que el primero solicitara encarecidamente al segundo consejo médico para Anne Conway. Poco tiempo después, Van Helmont visitaría a Lady Conway en la residencia de Ragley Hill. Esta visita no fue la última: exactamente al contrario, marcó el inicio de la permanencia casi constante de Van Helmont en Ragley Hill hasta la muerte de Anne Conway. Para este momento, Van Helmont ya estaba profundamente involucrado con Von Rosenroth en investigaciones en torno a la cábala judía, lo cual incluía su compromiso con el proyecto de edición de Kabbala Denudata. Sobre las mesas de Ragley Hill no pocas veces descansaron los textos que acabarían reunidos en el célebre volumen.

El 23 de febrero de 1679 Anne Conway moría acompañada por Francis Mercury van Helmont. Descansaba por fin tras jornadas de tortuosa agonía. Su testamento, redactado en 1673, incluía a Henry More y Francis Mercury van Helmont entre sus herederos.

\section{El neOplatonismo herReriano de Anne Conway}

Pasemos ahora sí a aproximarnos a la única obra surgida de la pluma de Lady Conway que ha llegado a nuestras manos. Del contenido de la misma es fácil suponer que probablemente se redactó entre 1675 y 1677, período inmediatamente anterior a la publicación de Kabbala Denudata y coincidente con la presencia afianzada de Francis Mercury van Helmont en Ragley Hill.

En 1690 aparece en Ámsterdam un volumen anónimo titulado Opuscula Philosophica quibus continetur, principia philosophiae \& recentissimae ac philosophia vulgaris refutata quibus junctur sunt C.C. problemata de revolutione animarum humanorum. Se trataba de un volumen colectivo que recogía tres obras distintas; posteriormente se reconocería la autoría de Anne Conway para la primera de ellas. En Londres, dos años después, aparecería una traducción al inglés de la primera edición en latín (la cual es a su vez una traducción del original inglés perdido), llevada a cabo por John Clark, discípulo y admirador de Van Helmont. Ambas versiones han llegado a nuestros días ${ }^{12}$.

\footnotetext{
${ }^{12}$ A. Conway, The Principles of the Most Ancient and Modern Philosophy, ed. P.
} 
La obra que aquí nos ocupa, y conforme al prefacio de la edición original de 1690, probablemente fuera recopilada por Van Helmont para su traducción y publicación, ya que los textos que la componían originalmente se hallaban dispersos pues consistían en anotaciones de carácter privado. Se trata en consecuencia de una obra fragmentaria por definición:

Editamos en tu honor este Opúsculo, que fue escrito hace no muchos años por una Condesa inglesa, mujer erudita más allá de su sexo, gran conocedora de la literatura Latina y Griega, y sumamente versada en toda clase de Filosofías. Imbuida en un primer momento en los principios de Descartes, y vistos sus defectos, descubrió después tantas cosas en la lectura de algunos escritores de la genuina Filosofía de la Antigüedad, que escribió estos pocos capítulos para su uso personal, pero con una letra muy oscura y minutísima. Al ser descubiertos después de su muerte, parte de ellos fueron transcritos (pues los que quedan apenas han podido ser descifrados hasta hoy) y traducidos al Latín, a fin de proporcionar alguna utilidad a todo el mundo de las Letras. Aquí están, pues, a disposición pública, para que todo aquel que quiera pueda admirar a su autora, reconocer la Verdadera Filosofía y evitar más fácilmente los errores ¡ay! Demasiado comunes. De todo ello disfruta y Vale ${ }^{13}$.

De todas las preguntas que sugiere el prefacio de los Principia, aquí nos centraremos en la que oculta la mención a la «genuina Filosofía de la Antigüedad»: cuál era esa filosofía y cuán antigua era realmente. Responder a esta pregunta exigiría profundizar en una serie de conceptos, circunstancias históricas, personajes y tradiciones que confluyen de manera determinante en las páginas de Anne Conway. Se trataría de una

Lopston, International Archives of the History of Ideas Vol. 101 (The Hague-BostonLondon 1982). Esta edición recoge las versión latina publicada en Ámsterdam en 1690 y la traducción de John Clark de 1692, respetando en este último caso la ortografía inglesa original del siglo XVII. Existe una edición más reciente del texto consistente en una traducción de la versión latina del XVII al inglés moderno: A. ConwaY, The Principles of the Most Ancient and Modern Philosophy, eds. A. P. COUdERT y T. Corse (Cambridge 1996).

${ }^{13}$ Principia Philosophiae, Prefacio, s.n. [En lo sucesivo, PRPH, seguido de capítulo y parágrafo]. Citamos por la edición española: Principios de la Más Antigua y Moderna Filosofía acerca de Dios, de Cristo y de la Criatura es decir acerca del Espíritu y la Materia en general, en La Filosofía de Lady Anne Conway: Un proto Leibniz: "Principia philosophiae antiquissimae et recentissimae”, ed. B. ORIO DE Miguel (Valencia 2004). Este trabajo debe mucho a su pormenorizado estudio introductorio. 
labor contextual que excede los límites de este trabajo más sobre lo que cabe señalar algunos elementos fundamentales.

El siglo XVII heredó del XVI el tópico que afirmaba la existencia de una cadena de saber que se remontaba a la Ley revelada por Dios al pueblo de Israel en el Monte Sinaí. Esta cadena de transmisión incluía instancias reales y míticas que hacían convivir a Moisés, Hermes Trismegisto, Zoroastro, Orfeo, Pitágoras, Sócrates y Platón; gnoseológicamente hablando, Atenas era considerada un suburbio jerosolimitano y Platón, un discípulo de Moisés. Esta sabiduría, susceptible de ser rastreada en las venerables escrituras de la Antigüedad, era denominada Prisca Theologia o Prisca Sapientia, unificaba filosofía y teología y procedía de una única y divina fuente. Su relevancia radicaba en que podía proporcionar un verdadero y firme conocimiento de Dios y sus arcanos, lo cual incluía su creación, esto es, el mundo natural objeto de estudio de la ciencia. Este gesto arqueológico que buscaba la verdad en filosofías aparentemente perdidas y arcanas se repite en Van Helmont y Conway, quienes identificarán cábala judía -en tanto «la auténtica sabiduría de los hebreos»- y Prisca Theologia, convencidos de la antiguiedad y consecuente valor de la primera.

Es preciso además añadir algunas pinceladas mínimas a nuestro cuadro de época para poder apreciarlo con mayor nitidez. Resulta pertinente hacer alusión, a fin de llevar a cabo una contextualización eficaz de la obra de Anne Conway, a otros temas fuertemente arraigados en el siglo XVII, legados también de la tradición neoplatónico-cabalística surgida en el Renacimiento. El primero de ellos consiste en la afirmación del universo como una totalidad orgánica, donde cada parte refleja a las otras. En esta totalidad orgánica absolutamente todo está conectado por una red de simpatías; esto se ve favorecido allí donde no existe una diferencia esencial entre espíritu y materia, que sólo se diferencian en el mero hecho de ser manifestaciones diversas de un mismo continuo ontológico. Súmese a ello que el universo no es considerado estático; por el contrario, se encuentra en un continuo proceso de cambio y evolución a la manera de una transmutación alquímica que culminaría con su restablecimiento al estado de pureza espiritual previo a la caída sobrevenida por el pecado original. En este universo el hombre ha sido creado por Dios a su imagen y semejanza y comparte la naturaleza divina; este parentesco lejano pero 
real con la divinidad le confiere una responsabilidad ineludible como conductor y en gran medida artífice del proceso que conducirá todas las cosas a su redención e identificación con la unidad primigenia. El pensamiento y la imaginación, por último, resultan instrumentos gnoseológicos que permiten al hombre comprender diferentes niveles de realidad así como acceder al oculto conocimiento divino.

El párrafo anterior, aunque de manera sucinta y esquemática, describe el marco general en el cual se inscribe la filosofía de Anne Conway así como muchos de los presupuestos de los que parte. Nos toca ahora referirnos a los estudios hebreos como la veta que Conway, Von Rosenroth y Van Helmont escogieron para extraer el metal precioso de la Prisca Theologia. Como ya se ha mencionado, la llegada de los textos cabalísticos a manos de Lady Conway tiene una historia muy clara: la del proceso de edición de Kabbala Denudata por la colaboración conjunta de Christian Knorr von Rosenroth y Francis Mercury van Helmont. Detengámonos brevemente en esa historia.

Christian Knorr von Rosenroth no sólo era un versado hebraísta. Sus estudios abarcaban asimismo teología, derecho, filosofía, filología, historia, numismática y ciencia natural. En materia de idiomas, manejaba a la perfección -además del alemán, su lengua materna- latín, griego, hebreo, arameo, siríaco, árabe, francés, holandés, inglés y español. Había estudiado hebreo y misticismo judío bajo la tutela de Tomás de Pinedo (1614-1679), Isaac de Rocamora (1601-1684) y Rabí Meir ben Juda Levi Stern (d. 1679), todos ellos judíos, los dos primeros de origen marrano.

En relación al interés por el hebraísmo de Von Rosenroth y Van Helmont es pertinente aclarar que no representaban un caso excepcional en la época. Desde el Renacimiento se había producido en Europa un creciente interés en los estudios hebraicos por parte de teólogos cristianos. Estos se volcaron en el estudio de la lengua hebrea como un instrumento para profundizar en su conocimiento y comprensión de las Sagradas Escrituras. Guiados por la lengua original del Antiguo Testamento, se sumergieron en un mundo de leyes, exégesis, mística y filosofía judías ${ }^{14}$. Se advirtió entonces no sólo la riqueza, sino el elevado potencial explicativo de la tra-

${ }^{14}$ Véase M. Goldish, Judaism in the Theology of Sir Isaac Newton (Dordrecht 1998) págs. 1-37. 
dición judía. Su universo literario podría esclarecer cuestiones relativas a la naturaleza de las profecías apocalípticas, cosmogonía, cosmografía, el pasado pagano y cristiano, cuestiones de índole metafísica y cualquier tema que guardara relación con las verdades contenidas en el Libro de la Escritura.

Durante los siglos XVI y XVII los estudios hebreos tuvieron un rápido y fértil desarrollo como consecuencia tanto del humanismo renacentista como de la Reforma Protestante. Los humanistas se interesaron en el hebreo como el tercer idioma de la antiguiedad, junto al griego y el latín. El interés de los protestantes en la lengua hebrea radicaba en su convicción de que sólo se podrían comprender con propiedad las Escrituras leyéndolas en sus lenguas originales ${ }^{15}$. Esto hace que desde el siglo XVI contemos con célebres figuras dedicadas al hebraísmo: Johannes Reuchlin, Sebastian Münster, Martin Bucer, Egidio de Viterbo y Martín Lutero. El ímpetu de estos intelectuales y otros más permitió que los estudios hebreos constituyeran paulatinamente parte regular de los estudios curriculares de las universidades europeas. Ya en la primera mitad del siglo XVII, los esfuerzos de Johannes Buxtorf El Joven y El Viejo dieron un nuevo impulso a dichos estudios ${ }^{16}$. La labor intelectual de los Buxtorf incluyó la producción de gramáticas, léxicos y bibliografía sobre tradición judía que resultaron fundamentales para el desarrollo autodidacta de los estudios hebreos durante el siglo XVII. Simultáneamente, la escuela de Scalígero y sus colegas en Alemania y posteriormente en los Países Bajos produjeron

${ }^{15}$ Existe una amplísima bibliografía sobre el auge del hebraísmo en los siglos XVI y XVII y su vínculo tanto con el humanismo renacentista como con la Reforma Protestante. Entre otros títulos es posible mencionar: J. Friedman, The Most Ancient Testimony: Sixteenth-Century Christian-Hebraica in the Age of Renaissance Nostalgia (Athens 1983); G. Lloyd Jones, The Discovery of Hebrew in Tudor England: A Third Language (Manchester 1983); A. L. Katchen, Christian Hebraists and Dutch Rabbis: Seventeenth Century Apologetics and the Study of Maimonides' Mishne Torah (Cambridge 1984); J. van Den Berg y E. G. E. van DER WALL (eds.), Jewish-Christian Relations in the $17^{\text {th }}$ Century. Studies and Documents (Dordrecht 1988); R. H. Popkin y G. M. WeInER, Jewish Christians and Christian Jews: From the Renaissance to the Enlightenment (Dordrecht 1994); A. P. Coudert, S. Hutton, R. H. Popkin y G. M. Weiner (eds.), Judaeo-Christian Intellectual Culture in the Seventeenth Century (Dordrecht 1999).

${ }^{16}$ Sobre los aportes de los Buxtorf al campo del hebraísmo véase S. G. BuRnEtT, From Christian Hebraism to Jewish Studies: Johannes Buxtorf (1564-1629) and Hebrew Learning in the Seventeenth Century (Leiden 1996). 
excelentes traducciones desde el hebreo a las que anotaron y enriquecieron con estudios de su autoría. Por la misma época se produjo una revitalización del estudio de la cábala: Johan Stephan Rittahngel publica en 1642 su traducción del Séfer Yeșirá, un gesto predecesor de la Kabbala Denudata de Van Helmont y Von Rosenroth.

La elaboración de Kabbala Denudata, perseguía el objetivo de ofrecer al lector culto europeo los textos más representativos de la tradición cabalística. Las obras en cuestión aparecían acompañadas por un aparato de comentarios redactados por Von Rosenroth, Van Helmont y -en menor medida y acierto- por Henry More. Tales comentarios tenían por propósito facilitar el acceso y la comprensión de aquellos abstrusos textos que por primera vez se ponían a disposición de un público más amplio, en general ajeno a la tradición judía. Entre los textos que se editaron en este conjunto destacaba una de las obras más relevantes entre las producciones de su género: el Séfer ha-Zóhar de Moisés de León. Se incluyeron además obras atribuidas a Isaac Luria y de sus discípulos, principalmente Hayim Vital (1543-1620). También se incluyó el tratado Puerta del cielo, de Abraham Cohen de Herrera, discípulo de Israel Sarug, quien fuera el máximo difusor de la cábala luriánica en Italia entre los años 1592 y 1598.

Debido a la labor divulgativa de Kabbala Denudata, el Zóhar pasó a ejercer una fascinación semejante en el público europeo a la que ya detentaban obras como los Hermetica, los Orfica o los Oráculos sibilinos. Al igual que estas, el Zóhar y el resto de los tratados cabalísticos de corriente luriánica fueron pensados como mucho más antiguos de lo que realmente eran. Pasaron de hecho a constituir el eslabón inicial de aquella mítica cadena de sabiduría ya que reproducían directamente y sin aditamentos paganos la sabiduría revelada por Dios, primero a Adán en el paraíso y luego a Moisés en el Sinaí. Desde su legitimidad en tanto una sabiduría divina y por tanto absoluta, procedente del fondo mismo de los tiempos, la cábala podía proporcionar soluciones interpretativas a problemas científicos típicos de la época, como el de la relación mente-cuerpo y espíritu-materia. Conocimiento de los arcanos divinos, conocimiento del mundo natural y perfeccionamiento ontológico confluían por tanto en un mismo proyecto científico y ético.

También de cara a contextualizar el pensamiento herreriano y su impacto en Conway hemos de tener presentes algunos de los elementos 
principales de la tradición luriánica ${ }^{17}$. Mencionaremos primero la gran novedad respecto de la tradición zohárica. Para esta -en línea con la filosofía neoplatónica- el primer acto del Dios-Uno había consistido en una emanación, como consecuencia de un desbordamiento ontológico. En el sistema de Luria, por el acto del Șimșum la divinidad no emana, sino que se retrae para dejar un hueco donde pueda darse un lugar para la creación del mundo. Es decir: si todo está colmado por la divinidad, esta habrá de retirarse para dejar algo vacío de su presencia. El mundo por tanto tiene su origen en la privación, en el retraimiento, en el apartamiento de Dios de su lugar. Esta nueva forma de interpretar la creación supone una forma de blindar el proceso a las implicaciones panteístas tan afines con la doctrina de la emanación. Se trata de un sistema puramente teísta en la medida en que el primer acto de la divinidad es su determinación voluntaria como una instancia otra del mundo; o mejor dicho, la determinación del mundo y la fundación de su otredad respecto de Dios.

Cuando la divinidad se retira, quedan en ese hueco primordial (Tehirú) esquirlas de luz divina, rastros de la divina presencia (Rešimú) que Isaac Luria describe metafóricamente como las gotas de aceite o vino que permanecen en la botella aún después de ser vaciada. En el espacio originado por la retirada de la divinidad se forma Adam Cadmón, el hombre primordial, la primera emanación de En-Sof, la divinidad infinita e indeterminada. De Adam Cadmón surgen también por emanación y de forma connatural a él las luces de las sefirot, esto es, los «poderes» con los que la divinidad actúa en el mundo y mantiene su equilibrio por medio de una tensión y concurrencia de fuerzas opuestas. El Adam Cadmón representa algo así como el arquetipo previo a la emanación, continente de

${ }^{17}$ Para una explicación de estos conceptos en el contexto de la escritura herreriana véase: G. Scholem, «Introduction» a A. Cohen de Herrera, Das Buch Sha'ar haShamayim oder Pforte des Himmles (Frankfurt 1974); G. Scholem, Avraham Kohen Herera, ba'al "Sha'ar ha-Shamayim" (Jerusalem 1978); A. Altmann, «Lurianic Kabbala in a Platonic Key: Abraham Cohen Herrera's Puerta del Cielo», Hebrew Union College Annual 53 (1982) págs 317-355; K. KRABBENHOFt, «Introducción»a A. Cohen de Herrera, Puerta del Cielo (Madrid 1987); K. Krabbenhoft, «Kabbalah and Expulsion: The Case of Abraham Cohen de Herrera», en The Expulsion of the Jews: 1492 and After, eds. R. B. Waddington y A. H. Williamson (New York 1994); N. Yosha, Mitos u-metaforah: ha-parshanut ha-filosofit shel R. Avraham Kohen Hererah le-kabalat ha-Ari (Jerusalem 1994). 
las sefirot, vehículos arquetípicos emanados, configuradores de la luz que emana de En-Sof. Estas sefirot han de ser imaginadas como recipientes de la luz divina, donde contenido y continente conforman una unidad. Pero el Adam Cadmón no pudo formarse enteramente a raíz de una sobreabundancia de la luz de En-Sof que los recipientes no fueron capaces de contener, estallando en pedazos y produciendo la Šebirá ha-Kelim («ruptura de los recipientes»).

Esto supuso que los poderes creativos de la divinidad, que incluían tanto fuerzas permisivas como restrictivas, principios femeninos y masculinos, positivos y negativos, se precipitaran en desorden y desequilibrio dentro del Tehirú. Como en todos los dramas cósmicos, esta catástrofe no sólo era inevitable, sino querida por Dios. La Šebirá ha-Kelim supone la entrada en escena de la materia determinada y diferenciada, una materia formada a partir de los pedazos de los recipientes (quelipot), la luz sefirótica que fueron capaces de conservar y las chispas de luz divina que En-Sof había dejado tras de sí al retirarse mediante el acto del Șimșum. Sólo mediante la reparación del daño se podría acabar con la diferenciación y con la caótica mezcla de potencias divinas. En este drama existencial, la restauración del orden perdido y la restitución (Ticún) al seno de En-Sof es la meta de todo lo creado.

Atendamos a la afirmación que cierra el párrafo precedente. El drama luriánico no es puramente antropocéntrico y es importante insistir en ello: absolutamente toda la creación está involucrada en el proceso de redención, porque absolutamente todas las criaturas contienen en su materia esquirlas de las luces desbordadas. Estamos por tanto ante un monismo sustancial que no reconoce diferencias entre materia animada e inanimada, ya que absolutamente toda la realidad natural está imbuida y colmada de presencias espirituales. Pero el estado de estos espíritus presentes en el mundo es el exilio y la dispersión; corresponde al hombre propiciar su reencuentro con la unidad divina. Aquí volvemos a encontrarnos con una escena familiar para la tradición renacentista neoplatónica: la del hombre que se transforma en un mago capaz de controlar fuerzas cósmicas. En este caso no se opera por medio de talismanes, plantas, minerales, afinidades astrológicas varias u otras formas de magia simpática, sino simple y llanamente por el perfeccionamiento ético y moral: cada buena obra actúa como un peldaño ascendente hacia el paraíso para los espíritus exiliados; 
de forma inversa, cada pecado los confina a los calabozos de la más grosera materialidad.

La perspectiva es más optimista de lo que pueda parecer en un primer momento, ya que el retorno del exilio de la divinidad, el alejamiento de la materialidad, del mal y del dolor es un proceso necesario hacia el cual constantemente se encamina el conjunto de los seres. El cumplimiento del Ticún no es otra cosa que la culminación de la historia; un desenlace necesario que tendrá lugar antes o después, una promesa mesiánica por cumplir. El sistema de Isaac Luria escenifica un drama cósmico donde se juega la salvación universal. El cabalista ya no puede aspirar al retraimiento melancólico: tiene una urgente e ineludible responsabilidad con la totalidad de las especies creadas y consigo mismo en cuanto tal. Las almas que insuflan cada uno de los elementos del mundo se hayan sumidas en un ciclo de constante transmigración, círculo de renacimiento que sólo se verá interrumpido cuando las mismas alcancen su plenitud ontológica en la unidad con lo divino. Esta doctrina de la reencarnación explica los padecimientos de una vida como un proceso expurgatorio de faltas cometidas en la precedente. Cada sufrimiento vital implica la purificación de un lastre, aligerando la carga en las encarnaciones posteriores hasta recuperar finalmente la naturaleza espiritual. Por tanto, en virtud de su propia naturaleza contingente, ninguna determinación, diferencia, cuerpo, mal o padecimiento podrían ser eternos en la medida que su naturaleza es contraria a la de la eternidad, atributo sólo predicable plenamente de Dios.

Knorr Rosenroth, Van Helmont y Conway suscribirán a esta visión optimista del Ticún que entiende los sufrimientos como instancias transitorias de purificación. Esto supondrá en los tres pensadores un quiebre con los dogmas católicos y protestantes relativos al juicio final, la salvación y el infierno. Van Helmont negará categóricamente la eternidad del infierno, doctrina que califica sin más de perniciosa por considerarla conducente al ateísmo. Los atributos divinos de bondad, justicia y misericordia quedarían demasiado en entredicho ante un dios capaz de condenar a las almas de los pecadores a una eternidad de tormentos, castigo desproporcionado con la breve duración de la vida terrenal, por más sumida en la iniquidad que esta haya estado.

Las ideas antes resumidas impregnaron la producción de Isaac Luria y las de sus discípulos y continuadores. Como hemos dicho, muchas de sus 
obras fueron seleccionadas por Van Helmont y Von Rosenroth para ser incluidas en el célebre compendio de escritos cabalísticos. El estudio de estos textos por Van Helmont, cuya residencia por aquellos años estaba prácticamente fijada en Ragley Hill, permitió que los mismos llegaran a manos de Anne Conway. Entre todos, uno de ellos fue leído y releído con fruición por nuestra autora. Se trataba del Porta Coelorum, según el título de la traducción al latín que ella manejó, procedente a su vez de una traducción al hebreo del original español ${ }^{18}$. Este tratado debía su autoría a Alonso Núñez de Herrera, judío de ascendencia española (su padre era originario de Córdoba) que había dedicado su juventud al oficio de agente comercial, llevando por tanto una existencia trashumante ${ }^{19}$.

Para el año 1619 Alonso Núñez se hallaba registrado en la comunidad judía de Ámsterdam bajo el nombre de Abraham Cohen de Herrera, permaneciendo allí -tal como lo atestiguan los archivos de dicha comunidad- hasta su muerte, acontecida el 14 de febrero de 1635. Son de sobra conocidas las razones que atraerían a un judío de origen ibérico a elegir Ámsterdam como residencia definitiva: la ciudad representaba un territorio de relativa tolerancia religiosa y se mostraba dispuesta a acoger en sus calles a las víctimas de las persecuciones religiosas que continuaron en la Península Ibérica después de la expulsión de los judíos en 1492 de los reinos de Castilla y Aragón y en 1497 del reino de Portugal. El Edicto

${ }^{18}$ Conforme a los datos que disponemos parece ser que Anne Conway no sabía suficiente hebreo como para leer un texto redactado en esa lengua. Todo parece indicar que ella trabajó sobre la versión en latín posteriormente recogida en $K D$ y que resulta un resumen del texto completo. En la redacción del presente trabajo hemos cotejado que los fragmentos citados del texto castellano se correspondan con los recogidos en el mencionado resumen realizado en el siglo XVII.

${ }^{19}$ Para más información sobre la biografía de Abraham Cohen de Herrera véase la «Introducción» de K. Krabbenhoft a Puerta del Cielo (Madrid 1987) págs. 12-19 [a partir de ahora citado por la abreviatura $P d C$, seguido de número de capítulo y parágrafo]. El Puerta del cielo, escrito por Cohen de Herrera en español, fue publicado por primera vez en la traducción hebrea que hizo Isaac Aboab de Fonseca y que llevaba por título Séfer Ša 'ar ha-Šamáyim (Amsterdam 1655). Tiempo después una selección de estas obras se tradujo al latín, apareciendo en la Antología de escritos cabalísticos titulada Kabbala Denudata (Sulz-Bach 1678) t. 1, parte III, págs. 1-102. Aunque no la hemos tenido en cuenta por haberse publicado posteriormente a la redacción de nuestro trabajo, cabe mencionar la reciente edición del texto llevada a cabo por M. BeLtrán, Abraham Cohen de Herrera. Puerta del cielo (Madrid 2015). 
de Expulsión firmado por los reyes católicos produjo el exilio de todos aquellos que no estaban dispuestos a aceptar el bautismo como precio por permanecer en suelo castellano-aragonés. La gran mayoría partiría rumbo a Portugal -de donde también serían expulsados en 1497- y al Magreb, además de la Península Itálica, Turquía, Grecia, los Balcanes, Palestina, etc. Pero un nutrido grupo, en el cual se encontraba la familia de Alonso Núñez de Herrera, decidió en un principio permanecer en España y más tarde en Portugal aceptando exteriormente el bautismo católico pero practicando en la clandestinidad los ritos judíos ${ }^{20}$.

Tanto en España como en Portugal estos cristianos nuevos ocuparon posiciones de privilegio que hasta entonces les habían estado vedadas: en el comercio, la vida cortesana e incluso en el seno de la Iglesia. Este vertiginoso ascenso social de los cristianos nuevos no produjo precisamente simpatías entre la comunidad de cristianos viejos, con lo cual la persecución de aquellos se vio estimulada. Ante la ola de violencia que se produjo contra ellos, sumada al acecho inquisitorial, muchas familias criptojudías partieron rumbo a los Países Bajos, donde retornaron a la fe de sus ancestros de forma pública y en pleno derecho. De esta forma, en la comunidad judía de Ámsterdam la presencia de los sefardíes resultaba por demás notoria: eran ex cristianos nuevos devenidos en judíos nuevos ${ }^{21}$. Uno de los aspectos más sobresalientes fue la impronta del legado hispanolusitano en las producciones intelectuales de la comunidad, que asumían el castellano y el portugués como vehículos dignos de transmitir ciencia,

${ }^{20}$ Existe una amplísima bibliografía sobre la historia del judaísmo hispano-lusitano y su trayectoria después de los decretos de expulsión. Los trabajos de J. CARo BAROJA, Y. Baer, B. Netanyahu y D. Ruderman son ya clásicos de referencia. Existen estudios de carácter generalista más actuales entre los que es posible mencionar: H. MÉchoulan (ed.), Los judíos de España: Historia de una diáspora (1492-1992) (Madrid 1993); E. BenBASSA y A. Rodrigue, Historia de los judíos sefardíes. De Toledo a Salónica (Madrid 2004); J. Pérez, Los judios en España (Madrid 2005).

${ }^{21}$ Sobre la especificidad de la comunidad judía de Ámsterdam en el siglo XVII hay algunos trabajos de referencia obligada, entre ellos: Y. H. Yerushalmi, The Re-education of Marranos in the Seventeenth Centtury: The Third Annual Rabbi Louis Feinberg Memoral Lecture (Cincinnati 1980); G. AlBIAC, La sinagoga vacía. Las fuentes marranas del espinosismo (Madrid 1987); Y. Kaplan, From Christianity to Judaism: The Story of Isaac Orobio de Castro (Oxford 1989); R. H. PopkIN, «The marranos of Amsterdam», en The Third Force in Seventeenth-Century Thought, ed. R. H. PopkIN (Leiden 1992) págs 149-171, Y. KaPLan, Judios Nuevos en Ámsterdam (Barcelona 1996). 
filosofía, poesía y otras manifestaciones culturales. Por su parte, los libros de oraciones se traducían del hebreo al castellano y al portugués y se componían nuevas oraciones en estas lenguas, que también eran utilizadas en los oficios sinagogales. Esta preeminencia de los idiomas castellano y portugués sobre el hebreo entre muchos de los judíos de Ámsterdam pudo ser la causa de que Herrera redactara su tratado cabalístico -un género en el cual el hebreo y el arameo habían sido los idiomas tradicionales- en lengua castellana.

Abraham Cohen de Herrera, en su errática trayectoria, recaló en Italia antes de establecerse en Holanda, donde estudió los diálogos de Platón, las Enéadas de Plotino y los Elementos de teología de Proclo, en la traducción llevada a cabo por Marsilio Ficino. De este último también conoció su Teología platónica y, de su mano, Herrera se familiarizó con el sincretismo italiano que reunía en una misma mesa la teología escolástica, el platonismo, el neoplatonismo, la filosofía árabe y judía medieval y el hermetismo ${ }^{22}$. Traducirá a su vez obras de León Hebreo, Torcuato Tasso, Julio César Escalígero y Francisco Suárez y realizará glosas sobre textos de Domingo Báñez, Francesco Patrizi y Benito Pereira. Traducirá también pasajes de Dionisio Pseudo Areopagita y Pico della Mirandola.

Con este bagaje filosófico, Herrera se encontrará con Israel Sarug en la última década del siglo XVI. Herrera estaba persuadido de que Sarug era un auténtico discípulo de Isaac Luria. Sarug, el cual, aunque no había conocido en vida a Luria sí que fue un gran difusor de sus doctrinas, a la vez que defendía la identidad entre cábala y filosofía. Representaba una corriente de cabalismo neoplatónico que simpatizaba con la filosofía de Pico della Mirandola, adoptando un eclecticismo que sin duda favoreció la empatía con Herrera. Sin embargo, este último siempre priorizó como fuente de verdad la tradición oral revelada a Moisés y transmitida por los sabios del pueblo judío, entre los que menciona a grandes representantes de la corriente luriánica como Moisés Cordovero y al propio Israel Sarug, su maestro ${ }^{23}$.

${ }^{22}$ En relación al sincretismo realizado por Herrera entre cábala y neoplatonismo véase Altmann, «Lurianic Kabbala».

${ }^{23}$ Esta convicción queda claramente expresadas en las siguientes palabras de Abraham Cohen de Herrera: «Breve introducción y compendio de alguna parte de la divina sabiduría q(ue) por tradisión vocal y sucesiva vino de Mosseh nuestro preceptor y maestro a los 
En virtud de lo antedicho, en las páginas de Puerta del cielo observamos una armónica convivencia de la tradición cabalística con la filosofía y teología pagana y cristiana. Del primer grupo destaca la influencia del Séfer Yeșirá, que es constantemente citado por Herrera. El texto en cuestión se trata del primer compendio sistemático de la cábala, redactado en Palestina entre los siglos III y VI y conforme a la tradición de las falsas atribuciones como garantía de legitimidad, Herrera atribuye la autoría del mismo tanto a su homónimo patriarca bíblico como a Akiba ben Yosef, cuyo nacimiento se calcula alrededor del año 40 a. C. Este tratado, que será rescatado en los siglos XVI y XVII por los defensores del naturalismo lingüístico, describe la creación como un proceso de combinación de las veintidós letras del alfabeto hebreo, que no serían otra cosa que el material mismo del mundo, sus «bloques» constitutivos ${ }^{24}$. De todas formas, el andamiaje metafísico principal de Puerta del cielo procede de la escuela de Safed: Moisés Cordovero, Isaac Luria y Hayim Vital.

Las fuentes citadas de tradiciones ajenas al judaísmo son numerosas, pero vale la pena recoger algunas para acabar de formarnos una idea de la riqueza y pluralidad que subyacen a la obra de Abraham Cohen de Herrera. Entre ellas se cuentan los diálogos platónicos Timeo, Parménides y Banquete según la traducción y comentarios de Marsilio Ficino, así como las ya mencionadas Enéadas plotinianas; el Pymander y el Corpus Hermeticum; aparecen menciones a Jámblico, Proclo, Porfirio y Pitágoras. Del corpus aristotélico tenemos citas procedentes de la Física, Metafísica, De anima, De caelo y De generatione et corruptione. La tradición árabe y judía medieval aparece representada por el Tahafut al-Tahafut de

ancianos, a los profetas y sapientes del pueblo israelítico por merced del autor della y de todos los bienes de mí Ab(raha)m Coen de Herrera, hijo del honrado y prudente viejo Rabí David Cohen de Herrera, coligida de la ordinaria doctrina de R. Simeon ben Yohay, R. Mosseh Barnahman, R. Azariel, R. Ioseff Chequitilia מערכת הילהות y su espositor R. Iuda Hayat. R. Mosseh de León. R. Mehir Gabay, R. Menahe(e)m Recanati, Rabí Menahem Azaria de Fano y de otros cabalistas de loable memoria y principalmente del eminente Haham Rabí Mosseh Cordovero, que está em paz resebida, y platicada de la viva voz del Haham Rabí Israel Sarug de felice memoria, mi preceptor y maestro», $P d C$, I. Citamos por la edición: Abraham Cohen de Herrera, Puerta del Cielo, edición, estudio y notas de Kenneth KrabBenhoft (Madrid, 1987).

${ }^{24}$ Existe una edición castellana muy reciente del texto: Libro de la Creación, edición y traducción del hebreo de Manuel Forcano (Barcelona 2013). 
Averroes y por el Moré nebujim maimonideano. Entre las obras latinas con las que trabaja destacan, entre otras, La consolación de la filosofía de Boecio, las Cuestiones disputadas, de Tomás de Aquino y las Disputaciones metafísicas de Francisco Suárez. Aunque no cita directamente sus obras, también menciona los nombres de Johannes Reuchlin y Paracelso. Recurre asimismo a citas de autoridad reales y míticas a las que califica como «los más excelentes filósofos», recreando una cadena de saber que incluye los familiares nombres de Zoroastro, Mercurio Trismegisto, Orfeo, Pitágoras, Platón, Plotino, Porfirio, etc.

\section{Una lectura herreriana de los Principia de Conway}

Los elementos hasta aquí esbozados nos permiten sumergirnos finalmente en las páginas de los Principia y realizar su contrastación con la tradición cabalística en general y con Puerta del Cielo en particular. No se trata aquí de exponer la totalidad del texto de Conway, sino sólo aquellos puntos que responden a la propuesta de lectura presentada en este ensayo. Posiblemente una presentación tan fragmentada podría parecer una falta para con la autora o una criba demasiado forzada. No creemos que sea así. Sencillamente estamos recopilando sus afirmaciones respecto a uno de sus intereses, extraídas de un conjunto de afirmaciones reunidas a posteriori y que fueron producidas fragmentariamente, tal y como hemos explicado antes.

El capítulo primero de los Principia se abre con una descripción de los atributos de Dios, a quien se adjudica el papel de creador único de todas las cosas, visibles e invisibles ${ }^{25}$. Es una entidad que no conoce el cambio ni la composición, consistiendo en una unidad indivisible e inmutable, así como puramente espiritual ${ }^{26}$. Este es el primero de los tópicos en que una cita introducida por la autora ${ }^{27}$ nos conduce a las páginas de Herrera donde encontramos lo siguiente:

\footnotetext{
${ }^{25}$ PRPH, I: 1.
}

${ }^{26}$ PRPH, I: 2.

${ }^{27} P d C$, I: 1 . Se trata del fragmento al que hace referencia Conway en $P R P H$, I: 1 , cuando en una nota remite al «Philosophiae Kabbalisticae Dissertario c. 3 in Kabbalae Denudatae Tom. I, Part 3». Recuérdese que la versión de $P d C$ con la que trabajaba 
Ab eterno y antes de todas las demás cosas es necesario que haya y por consiguiente es cierto que huvo como también havrá siempre un eterno e incauzado cauzador de todo, que siendo por sí y no por otro, en sí y para sí y no en otro ni para otro, es necesario ser y por su esencia acto purísimo y libre de toda material y pasiva potencia, infinito bien y senzillísimo uno que en sí y por sí con inlimitada perfeción y suficiencia existe y consiste, y que como tal excediendo a las demás cosas sin tener proporción con ninguna dellas ni con todas juntas las contiene en sí con suma eminencia y senzilleza, produze, conserva, govierna y perficiona fuera de sí con su infinita bondad, potencia y sabiduría $[\ldots]^{28}$.

Anne Conway salvará, junto con Herrera, la distancia entre el creador y la criatura; este último afirma que la divinidad no guarda proporción con los seres creados, los contiene en sí, pero los perfecciona (actualiza) fuera de sí. Si bien la divinidad no existe separada de su creación, su esencia no es intercambiable por la de las cosas mundanas, mientras que todas las últimas tienen en su esencia la presencia divina. La divinidad engendra la pluralidad sin que esto suponga la multiplicación de su substancia única. Volveremos más adelante sobre esta cuestión.

En la forma en la que se expone el modo en el que Dios crea el mundo es donde Anne Conway ofrece a sus lectores una versión neoplatónica del misterio trinitario, versión susceptible a su juicio de ser abrazada tanto por judíos como por musulmanes. Afirma en Dios la presencia de la Idea $^{29}$ o palabra ${ }^{30}$ en concordancia y a través de la cual todas las cosas han sido hechas. Junto a la Idea se encuentra en Dios el Espíritu o Voluntad que, por proceder de él, no multiplica su esencia ni su substancia, la cual permanece siempre una y la misma. La Idea -término que seguidamente es reemplazado por «Sabiduría»- junto con la Voluntad no son entidades distintas de Dios sino modos distintos o propiedades de una misma sus-

Conway era la editada por Von Rosenroth y Van Helmont como parte de la Kabbalah Denudata bajo el título que cita la autora.

${ }^{28}$ PdC, I: 1.

${ }^{29}$ PRPH, I: 6.

30 «In Deo Idea est, quae ipsius est imago, vel verbum intra ipsum existens, quae in substantia vel essentia unum idemque est cum ipso, per quam non minu se ipsum cognoscit, quam omnes res alias, \& secundum quam imo perquam ideam vel verbum omnes creaturas factae sunt \& creatae», $P R P H, \mathrm{I}: 6$. 
$\operatorname{tancia}^{31}$. Anne Conway invita incluso a que se prescinda de la formulación de la Trinidad como «tres personas», allí donde esto hiere la sensibilidad de judíos y musulmanes y además no encuentra punto de referencia en las Escrituras.

Más avanzado el tratado, Anne Conway se preguntará por el sentido del verbo «crear» aplicado a la eternidad e inmutabilidad de Dios y directamente asociado a su naturaleza esencial. Lo problemático aquí es que si Dios es un ente perfecto e inmutable, que no conoce ni ha conocido cambio alguno en la medida que el movimiento y el cambio entrañan de suyo la conquista de una privación, Dios por necesidad siempre ha tenido que ser creador. Pensar en un Dios ocioso que un buen día decide poner en marcha la creación es algo contrario a su naturaleza. Por tanto, la subordinación del Hijo de Dios al Padre ha de ser ontológica, mas no temporal. La divinidad crea mediatamente a través de su Sabiduría, Palabra o Logos expresada en su primogénito. En la medida que el primogénito de todas las criaturas es el Hijo de Dios, arquetipo en el cual están contenidos todos los principios de las cosas mundanas, la creación de las mismas ocurre sin sucesión, es decir, simultáneamente en un sólo acto por el cual Dios crea una sustancia intermedia que es a la vez consustancial al creador y a la vez substrato de la futura pluralidad del mundo, contenida en la multitud de sus arquetipos. En Cristo, entendido como sabiduría y palabra del Padre, están contenidas todas las potencialidades, ya que todo lo que es y será es actualmente en él ${ }^{32}$. Cristo, en cuanto primogénito de la creación, detenta una función mediadora que canalizará el poder creador de Dios; la divinidad crea a través y en su hijo, raíz primordial de todas las criaturas:

"Jesucristo" quiere decir el Cristo íntegro, que es Dios y Hombre: en cuanto Dios, se denomina "Logos Ousios, Palabra Esencial de Padre"; en cuanto hombre es "Logos Proforicós, Palabra Expresada o Proferida", perfecta y sustancial imagen de aquella Palabra que está eternamente en Dios y perpetuamente unida con él, siendo su vehículo y órgano, como el cuerpo lo es respecto del alma $[\ldots]^{33}$.

\footnotetext{
${ }^{31} P R P H, \mathrm{I}: 3$.

${ }^{32}$ PRPH, 4: 1.

${ }^{33}$ PRPH, 4: 2.
} 
La cristología de Conway sigue paso a paso la doctrina herreriana del Adam Cadmón y así lo reconoce a continuación. Al igual que en la versión cabalista en la cual se apoya, insiste en reconocer a Cristo como anterior por naturaleza al resto de todas las criaturas que fueron traídas a la existencia por su mediación en cuanto vehículo del verbo creador. A la vez, vuelve a referirse a Cristo como sostén y substancia de todo lo creado. Dejando en claro cuáles son las fuentes de semejantes afirmaciones, en el primero de los títulos que resumen el capítulo $\mathrm{V}$ de los Principia Philosophiae Lady Conway afirma: «Los antiguos Cabalistas reconocieron a este Primogénito Hijo de Dios, a quien llamaron también Adam Celeste, Primer Adam, Gran Sacerdote» ${ }^{34}$. La argumentación que desarrolla seguidamente, respecto de la unidad de Cristo como la primera producción de la unidad divina y causa anterior a la pluralidad, parece directamente extrapolada de la que desarrolla Abraham Cohen de Herrera en Puerta del Cielo, de quien citamos a continuación un fragmento que ejemplifica de forma paradigmática su herencia neoplatónica:

Que de la cauza primera próxima e inmediatamente no proceda sino aquel solo perfectísimo efecto que nuestro mecubal y maestro siguiendo al divino autor del Zoar llama Adam Kadmon u hombre precedente y los demás cabalistas keter helion o sublime y primera corona se puede persuadir con estas razones, de que la primera es que del uno en cuanto uno no puede proceder sino uno, [...] es imposible que inmediatamente proceda más que un solo efecto de aquel uno, digo, que escluye de sí toda multitud y variedad de potencias, actos, atributos, intelecciones, inteligibles, voluntades, apetibles y operaciones y que en sí purísimamente consistiendo no puede tener ni tiene ninguna relación, habitud o proporción con otro. [...] y es la segunda razón, de que todos los que quieren que de la primera cauza procedan inmediatamente muchos efectos confiesan que no emanan de su única y senzillísima naturaleza que como tal no produxiera sino un solo efecto, porque del puro uno no procede demás que uno sino de la multitud de las ideas y representadoras especias y exemplares que en su divino entendimiento concibe y esplica y de la varia electión, determinación e imperio de su libre voluntad y beneplático que es sin duda poner multitud en el senzillísimo uno y determinados y varios

${ }^{34}$ PRPH, V. 
actos, atributos, relaciones y operaciones en la única y absoluta infinidad que todo excede ${ }^{35}$.

Anne Conway se apoya en estos textos porque su cristología pretende demostrar la existencia de una substancia intermedia entre Dios y las criaturas, hipótesis que encuentra claramente demostrable. Para hacerlo procede a enumerar sus cualidades, que son las mismas que las del Adam Cadmón herreriano ${ }^{36}$. Este ser intermedio será por su propia naturaleza menor que Dios, por lo tanto no compartirá con él la cualidad de inmutabilidad, pero por su naturaleza coeterna y consustancial al creador, esta mutabilidad sólo puede ser ejercida respecto del bien. Las criaturas son seres mutables por definición, tanto respecto del mal, lo cual supone su empobrecimiento ontológico, como respecto del bien, en un camino de enaltecimiento que las aproxima por semejanza al ser espiritual del primogénito divino.

Conway establece entonces una clasificación de entes en tres categorías: la primera, completamente inmutable, es decir Dios, de quien no podríamos decir que se inclina hacia la obtención de más bienes, porque tal afirmación sería contradictoria con su jerarquía de sumo bien; la segunda, mutable pero sólo hacia el bien se refiere a un ente «que siendo por naturaleza bueno, puede hacerse mejor ${ }^{37}$. En la última categoría se encuentran las criaturas, a las cuales Conway, en toda una exhibición de animismo barroco, caracteriza de buenas por naturaleza, pero mutables respecto del bien y del mal. Entre los dos extremos ontológicos que contienen la primera y la tercera categoría se encuentra el medio necesario contenido en la segunda.

Una vez establecida la existencia de esta substancia intermedia es necesario advertir que esto tampoco supone asumir que Dios se ha desentendido de su creación dejándola en manos de un vasallo subsidiario. Conway recalca que Dios está «inmediatamente presente en todas las criaturas, pues en verdad él está inmediatamente presente en todo, lo llena todo e incluso opera en todas las cosas de forma inmediata y en sentido propio» ${ }^{38}$. Aquí la argumentación se torna un tanto confusa: por un lado

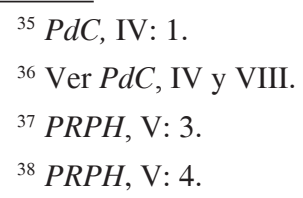


Conway defiende que aunque la divinidad opere inmediatamente sobre sus criaturas, utiliza el medio del Cristo-Adam Cadmón en virtud de la mayor proximidad ontológica de este con aquellas.

En cuanto al Hijo de Dios, Conway razona la pertinencia de llamarlo así ya que tal nomenclatura está más próxima a su naturaleza generada o emanada desde la divinidad. Hay un punto en el que Conway tendrá que distanciarse de Cohen de Herrera y tiene que ver con una circunstancia vital básica: ella es cristiana, no judía. Por ende, cree en el dogma de la venida en carne del Cristo-Mesías. Sin embargo, su elaboración de la encarnación se ve revestida de implicancias cabalísticas, ya que en concordancia con esta tradición, todo lo que existe por obra divina está revestido con un cuerpo vehicular, incluso Cristo antes de la encarnación. El Hijo de Dios viene a la tierra con un cuerpo celestial, «pues todo espíritu creado tiene su vehículo o terrestre o aéreo, o etéreo, como era este» ${ }^{39}$, asumiendo en el mismo parte de la naturaleza humana, esto es, de la naturaleza universal de las cosas, conforme a la noción de hombre como microcosmos a la que hemos hecho más de una referencia en el desarrollo del presente trabajo. Lo que sigue después es un relato de la Pasión donde lo que se resalta es la expurgación y redención de los pecados de la humanidad en los tormentos padecidos por Jesucristo, como momento previo a la liberación de las almas de la tiranía del tiempo, la corrupción y la muerte. Como Mesías encarnado, en su cuerpo sometido al tiempo y la mutabilidad se han de cebar las más encarnizadas torturas para que la expurgación y sanación de los males del mundo acontezca.

Si la redención de las criaturas es posible es debido precisamente a que no son estáticas; al contrario, son en virtud de su naturaleza creada mutables, por oposición a su causa inmutable ${ }^{40}$. Dios creó la materia, pero una materia animada que tiene en sí la capacidad de retornar a su estado espiritual originario, contenido como arquetipo en el seno del Adam Cadmón. Para comprender el proceso de mutación de las cosas, Conway vuelve a recurrir a la clasificación tripartita de entidades que había expuesto previamente para demostrar la existencia de una sustancia intermedia. Todos los fenómenos del universo pueden ser reducidos a estas

\footnotetext{
${ }^{39}$ PRPH, V: 6.

${ }^{40}$ PRPH, VI: 1.
} 
entidades: Dios, Cristo o Adam-Cadmón y las criaturas. Esta taxonomía englobaría todas las diferencias específicas perceptibles, así como la totalidad de los fenómenos mundanos. Anne Conway resume: todo cuanto puede ser denominado ente o bien es absolutamente inmutable (Dios), o sólo es mutable en relación al bien (Cristo) o es mutable tanto en relación al bien como al mal (las criaturas); no hay por tanto más entidades que las enunciadas. Dios posee una única substancia, al igual que su Primogénito. Pero Conway hace extensiva esta unidad de la sustancia a la «Creación Universal» que presenta en su especie una sola esencia. Rescatando el discurso paulino según el cual Dios creó todas las naciones de una sola sangre, considera que esto ha de extenderse al conjunto de las criaturas en su estado prelapsario. Anne Conway afirma por tanto la conexión simpática de todos los entes:

[...] así como Dios hacía a todas las naciones humanas de una misma sangre, a fin de que se amaran, se convivieran en armonía y se ayudaran mutuamente, de la misma manera también implantó Dios en las criaturas una simpatía universal y amor mutuo, que las convierte a todas en miembros de un mismo cuerpo y, (por así decirlo) hermanos, que tienen un único y común Padre, esto es, Dios en Cristo o Logos Encarnado, y también una sola Madre, aquella sustancia o entidad única de la que salieron y de la que son partes reales o miembros. Y aunque el pecado ha debilitado de modo asombroso en las criaturas este amor y simpatía, no lo ha destruido sin embargo de forma completa ${ }^{41}$.

Esta idea del total de la humanidad y las criaturas conformando una unidad por proceder de una única substancia encuentra su modelo en Puerta del Cielo, de donde es esperable que Conway haya extraído el argumento y la doctrina sintetizada. Herrera menciona una substancia «universalísima» de cuya explicatio resulta la multitud de especies y substancias. Adviértase cómo la instancia en la que confluyen las pluralidades es de naturaleza arquetípica o espiritual:

[...] cualquiera multitud se reduze a su unidad como la casi innumerable multitud de todos los hombres a una especie e idea humana y toda la multitud de las específicas e ideales unidades que necesariamente son en algún número determinadas se han de reduzir y reduzen a una soberana

${ }^{41}$ PRPH, VI: 4.

SEFARAD, vol. 75:2, julio-diciembre 2015, págs. 375-379. ISSN: 0037-0894. doi: 10.3989/sefarad.015.013 
unidad que común a todas las más las contiene en sí y esplica fuera de sí como por exemplo la universalísima sustancia a todas las específicas naturalezas y sustancias y a todas sus ideales unidades y exemplares cauzas, y así vemos que toda la multitud de las materias o sugetos se reduze a una primera materia o sugeto [...], todas las naturalezas a una universal naturaleza, todas las ánimas a una primera y perfectísima ánima, todas las vidas a una vida y finalmente todos los entendimientos e inteligibles esencias a un primero y perfectísimo entendimiento, inteligible y esencia $[\ldots]^{42}$.

Vemos cómo el monismo sustancial que habíamos atribuido a Von Rosenroth, Van Helmont y Conway aquí adquiere un matiz importante. Se trata de un monismo pero en el orden de las criaturas del mundo natural, ya que todas ellas son manifestaciones, modos, afecciones de una misma substancia; pero en esta última no se agotan las substancias o entidades existentes en el universo. Arrojando un nada sutil dardo contra Spinoza, Conway señala el error en el que incurren aquellos que afirman la existencia de una única substancia, lo cual haría a Dios intercambiable e identificable sin más con sus criaturas; Conway experimenta auténtico horror ante el Deus sive Natura de Spinoza. Por otro lado, recordemos que las acusaciones de panteísmo a las filosofías neoplatónicas han sido relativamente frecuentes a lo largo de la historia y por este motivo estas llevaron a cabo verdaderos malabares especulativos para salvar la trascendencia divina. Pero Anne Conway es teísta, como también lo fue Herrera, quien además se adscribía a un credo acérrimamente monoteísta. Herrera, en la senda de Luria y Sarug, ofrece un recurso interpretativo que los Principia recogieron posteriormente. El dios de Conway es por tanto un dios cabalístico-luriánico, un dios del Simṣum, más precisamente un dios herreriano, capaz de tener una presencia inmanente sin por ello menoscabar su trascendencia ni su insalvable distancia del mundo creatural.

Si Conway considera contrario a la realidad de las cosas $-\mathrm{y}$ por lo tanto impío- reducir todos los entes del mundo a una única substancia, no menos errado le parece postular sólo dos substancias, es decir, Dios y las criaturas. Una vez más, la existencia de un medio entre dos extremos le parece demostrable conforme a la necesidad natural de las cosas. Así lo han reconocido «los más sabios entre los judíos como algunos de

${ }^{42} P d C$, IV : 1. 
los llamados Gentiles, al admitir que se da un tal Medio, que los designaron con diversos nombres, como Logos, Hijo de Dios, Primogénito de Dios, Inteligencia, Sabiduría, Adam Celeste, etc.» ${ }^{43}$. La constancia histórica de semejante concepción filosófica, que no ha hecho otra cosa que mutar en sus nombres, entraña una vez más para Conway la garantía de universalidad del cristianismo a la vez que la verdad de sus convicciones filosóficas.

Lo importante aquí es que estas tres entidades marcan los límites de mutabilidad de las mismas y en ellas reposa el trasfondo neoplatónico de Conway, así como su adhesión a la doctrina luriana de la transmigración de las almas. Para exponer esto, la autora recurrirá a la metáfora de una escalera infinita que simboliza el orden de los seres, pero cuyos peldaños no pueden estar infinitamente distantes entre sí para posibilitar el ascenso y el descenso gradual por ella. La idea de un ascenso en grados progresivos también se encuentra expresada en Puerta del Cielo entre las conclusiones que cierran el tratado: «No pueden subir los inferiores a los altos y finalmente al altísimo si no es por graduales y proporcionados medios que los vayan conduziendo suavemente de un estremo a otro conligándolos todos entre sí encadenada y sucesivamente, y finalmente con su común y altísima causa ${ }^{44}$. Vemos cómo Herrera señala la importancia y necesidad no sólo del ascenso, sino de la progresiva unión de las criaturas, primero entre sí, conformando una ininterrumpida cadena del ser para posteriormente unirse a su causa. El reconocimiento de una filiación común a todas las criaturas indica aquí una condición previa para su reencuentro con el principio que las hermana.

Aunque infinita, es fácil deducir que en su ascenso esta escalera tiende hacia la divinidad inmutable y en su descenso a la materialidad corruptible. Qué determinará subir o bajar por ella no es otra cosa que la conducta de las criaturas, ya que en función de esta, las otras serán revestidas de un ropaje carnal apropiado para la naturaleza de su espíritu. Si un hombre se comporta en esta vida a la altura moral de un ángel, cabe esperar que en su próxima encarnación sea dotado de un cuerpo tan sutil y etéreo como el de los ángeles (que también son criaturas corporales); por el contra-

\footnotetext{
${ }^{43}$ PRPH, VI: 5.

${ }^{44} \mathrm{PdC}, \mathrm{X}$.
} 
rio, si posee un espíritu concupiscente y bestial, resultaría más apropiado otorgarle el cuerpo de una bestia, que resultará más acorde con sus instintos elementales. Más aún, el espíritu no hace otra cosa que configurar el cuerpo que habita con el poder de su imaginación y voluntad para proveerse de un ropaje coherente con sus inclinaciones.

De esta forma, el castigo del pecado consiste en el alejamiento del bien. Si el espíritu configura un cuerpo más grosero su alejamiento aumenta; si por el contrario se dota a sí mismo de un cuerpo cada vez más sutil, posee mayores recursos para aproximarse al bien. El infierno no es por tanto un lugar determinado en un espacio concreto ni mucho menos con una duración infinita, sino los peldaños descendentes, que son tantos como pecados cometidos y que ascienden conforme el alma cultiva su virtud. Al respecto nos llega como un eco la voz de Cohen de Herrera:

El premio y castigo se acomoda mejor por estos medios que son aquéllos con que a cada pecado sigue su tayamiento y retención de luz superior influencia y a cada buena obra su abertura y atraimiento de gracia y merced q(ue) tanto en unos y otros es más y mayor cuanto con más merecimientos van más abriendo las puertas del bien y atrayendo su influxo o con más culpas van cerrando las cataratas de la luz y quedando en más tinieblas privación y mal. También aquí se funda la penitencia que quita las nuves del castigo y atrae la luz de la misericordia, la eficacia de la oración que atándolos los altos con los baxos hace descender los altos a los baxos, hermoseando baxos de la luz y gracia de los altos y uniéndolos a todos entre sí y consigo y con su causa. [La cursiva es nuestra] ${ }^{45}$.

Así pues, en el sistema de Conway la justicia de Dios se expresa por el sistema de transmigración que hemos expuesto, pero la responsabilidad de las reencarnaciones recae por entero sobre la libertad de elección de los espíritus: son ellos los que con sus obras deciden ascender o descender por la escalera de los seres. El hombre se convierte en lo que ama: si busca unión con la divinidad, su naturaleza será gradualmente espiritualizada; si en cambio sus apetencias se limitan a la carne, este será su lastre en el ascenso ontológico. Pero para Conway absolutamente nada permanece en los peldaños inferiores. Los sufrimientos y castigos no son vanos, sino que

${ }^{45} P d C, \mathrm{X}$ : «Razones por qué hay [ ] coligidas por Abraham Cohen de Herrera, autor del precedente tratado». [El espacio en blanco señala un hueco en los manuscritos conservados que se han utilizado para elaborar la edición con la que estamos trabajando]. 
poseen una función purificadora «a fin de que el perdón prevalezca sobre la condena y esta se transforme en victoria para salvación y restauración de la criatura ${ }^{46}$. Este es un drama con final feliz cuyo escenario es el mundo concebido como un gran laboratorio alquímico donde los cuerpos han de ser quemados, fundidos y sublimados para su transmutación progresiva en el elemento áureo que contienen como marca de su origen divino. Citamos una vez más a Herrera:

[...] ordenando la cauza primera a sus efectos y encaminándolos por competentes medios al último fin que es ella misma, deve ordenar y encaminar a su perfectísimo efecto que es sin duda el primero a dicho fin tan próxima e inmediatamente cuanto es posible, mas esto no puede ser sino en un modo porque no hay variedad de grados sino es según más o menos se llegan o alexan a su principio y último fin de que se sigue que el q(ue) le es inmediato y sumamente cercano así en razón de su unidad y principio como de fin y perfectión es uno $[\ldots]^{47}$.

En este laboratorio de alquimia que es el mundo, la transmutación de las cosas se da en dos sentidos: los cuerpos pueden transformarse en espíritus y los espíritus en cuerpos allí donde la distinción entre ambos no es esencial, sino modal ${ }^{48}$. Ha quedado claro que la criatura es una única entidad o substancia que sólo varía en los modos de existencia, que pueden ser materiales o espirituales. Evidentemente el estado espiritual posee una jerarquía ontológica superior que el material, allí donde a mayor grado de espiritualidad mayor es la proximidad con Dios. Está en la naturaleza de la criatura ese acercamiento paulatino a la divinidad, ya que no es completamente extraña a ella: de hecho nada en el mundo lo es, no hay una sola especie completamente contraria a Dios, ni siquiera los demonios, quienes también retornarán del exilio que con su iniquidad se

${ }^{46}$ PRPH, VI: 8.

${ }^{47} P d C$, IV: 1.

48 «Como ya se ha demostrado más atrás, esta Criatura es una única Entidad o sustancia en cuanto a su naturaleza o esencia, de manera que únicamente varía en cuanto a los modos de existir, de los que la corporeidad es uno, que ofrece diversos grados según la cosa se acerque o se aleje más o menos del estado de cuerpo o de espíritu. Entre ambos estados el espíritu es el más excelente en el verdadero y natural orden de las cosas [...] es manifiesto que ninguna criatura puede hacerse más y más infinitamente cuerpo, aunque puede, por el contrario, hacerse más y más infinitamente espíritu», PRPH, VII: 1. 
han autoimpuesto. Lo malo sólo puede hacerse mejor, pero no peor, de la misma manera que la oscuridad siempre va hacia una mayor claridad. Asimismo, no hay algo así como puros cuerpos carentes de espíritu. Todo puede tender infinitamente hacia infinitos índices de bondad, luminosidad y espiritualidad, pero no hacia sus contrarios que resultan metafísicamente imposibles; en la naturaleza de las cosas no hay límites para su perfeccionamiento y acercamiento al bien, como sí los hay respecto del mal en tanto es una realidad puramente negativa.

Pertenece por tanto a la naturaleza de la criatura estar en perpetuo cambio y movimiento: de bien en bien, de bien en mal o viceversa. Pero ya hemos dicho que ninguna criatura puede derivar infinitamente hacia el mal ni permanecer eternamente en él. Esto lleva a Lady Conway a negar categóricamente la eternidad del infierno: todo suplicio ha de tener un sentido farmacológico y por tanto pasajero.

Otro motivo aducido por Conway para afirmar la conversión de los cuerpos en espíritus y viceversa es la ya mencionada imposibilidad metafísica de Dios de crear algo desprovisto de vida y bondad. Dios no ha hecho la muerte y por tanto tampoco ningún tipo de materia inerte. Este vitalismo es imprescindible para que el proceso de restitución sea viable: si una roca o un árbol son entendidos como seres desprovistos de almas, no sería posible pensar en la restauración de todo lo creado a la unidad primigenia. Aún las piedras participan en este retorno del exilio; hacia el final del tratado Conway introduce una cita procedente del Evangelio de Mateo que puede resultar muy ilustrativa de la cuestión que ahora estamos tratando: «Pues os digo que Dios tiene poder para suscitarle a Abrahán hijos de estas piedras» (Mt 3,9) ${ }^{49}$. Si Dios es capaz de sacar hombres de las piedras, en este contexto ya no sólo será en virtud de su poder milagroso, sino de la substancia común que hermana a rocas y hombres. La noción de materia inerte es además contraria al presupuesto de que las criaturas han de asemejarse en algo al creador.

El tercer argumento está sacado de la idea de amor como imagen de unidad:

[...] el fundamento de todo amor y de todo deseo, que lleva a una cosa hacia otra, consiste en que o ambos son de la misma naturaleza y sustancia o son semejantes entre sí o las dos cosas a la vez, o en que una obtiene

\footnotetext{
${ }^{49}$ PRPH, IX: 9.
} 
su ser de la otra. [...] Mas por encima de este amor específico, existe todavía algo del amor universal de todas las criaturas entre sí, más allá de la confusión producida por la transgresión: este amor procede de un mismo fundamento, a saber, que todas las criaturas son una misma cosa y como partes o miembros de un mismo cuerpo en razón de su primera sustancia o esencia ${ }^{50}$.

Más que un argumento en favor de la mutabilidad de los cuerpos en espíritus la cita que precede es otro alegato en favor de la unidad substancial de las criaturas. Sucede que estas reconocen su origen común, motivo por el cual sienten amor las unas por las otras colaborando en la cohesión de esa unidad. Por su parte el amor a Dios procede del reconocimiento de la filiación con él y en este acto se incrementa la semejanza que señala la naturaleza común.

Para finalizar con los objetivos de lectura que nos hemos propuesto, pasemos a la última afirmación de los Principia Philosophiae que proporciona una pista clara sobre el rastro del pensamiento herreriano en la pluma de Lady Conway. En el capítulo VIII, Anne Conway continúa dedicada a probar que la diferencia entre cuerpos y espíritus no es esencial, sino gradual. Para esto, expone el vínculo que se da entre ambos, en el cual los espíritus detentan el dominio de los cuerpos que ocupan, a los que conducen en vistas a llevar a cabo las diversas actividades que sus apetencias les dictan. Si se concibiera a los espíritus y a los cuerpos como absolutamente contrarios entre sí, en la medida que unos son divisibles y los otros indivisibles, unos penetrables y los otros impenetrables, no sería posible ningún vínculo ni operación de unos sobre otros. Es decir, si el cuerpo fuera una materia carente de vida, no cabría una relación posible. No hay por tanto tal distancia entre el cuerpo y el alma, siendo ambos de la misma substancia. Siguiendo una vez más a la cábala herreriana, Conway concluye parcialmente y nosotros con ella: « [...] se comprende fácilmente cómo el alma y el cuerpo están unidos entre sí, cómo el alma mueve al cuerpo y sufre con él y a través de él. (Que esta es también la opinión de los Hebreos puede verse en Kabb. Denud. [la cita es la última referencia del tratado a Puerta del Cielo])» ${ }^{51}$.

\footnotetext{
${ }^{50}$ PRPH, VII: 3 .

${ }^{51}$ PRPH, VIII: 2.
} 
Después de esta afirmación, sus argumentaciones discurrirán por otros andariveles, preparando el terreno para la introducción del noveno capítulo que cierra su obra. Allí todo el aparato previamente expuesto será utilizado en su furibundo ataque contra Descartes, Spinoza y Hobbes, autores a su juicio de una filosofía errada y engañosa, que no describe con justicia ni verdad la naturaleza del mundo. Pero este ataque ya no es el propósito de este trabajo

\section{ConClusión}

No es posible ni deseable someter a un reduccionismo contextual la obra de cualquier autor, sin embargo, una aproximación a los procesos sociales, históricos y culturales que rodearon su producción arroja mucha luz sobre la misma. Esto es especialmente importante con ciertos escritos, aquellos sobre las cuáles una lectura somera puede arrojar una condena lapidaria de marginalidad e intrascendencia. Los Principia Philosophiae pueden correr ese riesgo si no son leídos en relación a su contexto, a cuyas exigencias responden; sin unas mínimas coordenadas, sus palabras pueden ser reducidas sin más a los devaneos ociosos de una aristócrata que reunió en su residencia a un grupo de místicos y alquimistas y que leyó un par de textos antiguos sin orden ni concierto. Anne Conway, discurriendo sobre Dios, Cristo, el alma y los espíritus, no escribió una filosofía abstracta, pese a que la misma pueda resultar extranjera a nuestra sensibilidad contemporánea. Muy por el contario, su filosofía es una filosofía de la vida, del cuerpo, del mundo, de la naturaleza, a la cual pretendía conocer y explicar y a la cual consideraba algo más que una realidad a sojuzgar. Su física espiritualista será un protagonista indiscutido de la Revolución Científica y aún de lo que vendría después.

A su vez, la influencia de Cohen de Herrera en las disputas científicas del siglo XVII constituye un capítulo por explotar. Debates vinculados con la inmanencia de la divinidad en el mundo son los que propiciaron el desarrollo de una física que contemplara la presencia real de la materia espiritual no-extensa en la naturaleza, es decir, el destronamiento del mecanicismo cartesiano. Detenernos en figuras como la de Abraham Cohen de Herrera no se trata (o no debería tratarse) de un gesto condescendiente $\mathrm{y}$ arqueológico respecto de un pasado remoto y superado ante el des- 
pliegue de la racionalidad. Muy por el contrario, se trata de atender a las voces de ese pasado sin desagregar la riqueza sincrética de su realización histórica. Los elementos que lo componen, lejos de tratarse de accesorios prescindibles, resultan inalienables de la filosofía que los contiene, a la cual contribuyeron directamente a forjar en un proceso de influencia e imbricación mutuas, donde una y otra vez las fronteras entre magia, mística, filosofía y ciencia -aun en plena Modernidad- se tornan demasiado difusas para aspirar a una demarcación definitiva.

Recibido: 22/05/2015

Aceptado: 01/10/2015 